The processing of oil refining waste is essential from economic and environmental points of view. An important issue is the processing of soapstock to extract fatty acids, which are raze materials for various industries.

The two-stage method of fatty acids obtaining from soapstock using saponification with sodium hydroxide solution and decomposition with sulfuric acid is investigated.

The peculiarity of the work is the study of the influence of soapstock saponification conditions on the key efficiency indicators of fatty acid extraction: yield and neutralization number.

A sample of soapstock was obtained as a result of alkaline neutralization of sunflower oil. Soapstock quality corresponds to DSTU 5033 (CAS 68952-95-4): mass fraction of total fat $-68.5 \%$, fatty acids - $62.6 \%$, neutral fat $-5.9 \%$.

Rational saponification conditions were determined: duration ( $85 \mathrm{~min}$.) and concentration of sodium hydroxide solution (45\%). After saponification, the soapstock was subjected to decomposition with sulfuric acid under the following conditions: temperature $90{ }^{\circ} \mathrm{C}$, duration $40 \mathrm{~min}$. Under the rational saponification conditions, the yield of fatty acids $(91.8 \%)$ and the neutralization number $(187.1 \mathrm{mg}$ $\mathrm{KOH} / \mathrm{g}$ ) were determined. The obtained fatty acids correspond to the first-grade fatty acids according to DSTU 4860 (CAS 61788-66-7). Acid indicators: mass fraction of moisture and volatile substances $-1.5 \%$, mass fraction of total fat $-98.0 \%$, cleavage depth $-69.2 \%$ oleic acid.

The use of the soapstock saponification stage before decomposition leads to an improvement in the quality indicators and an increase in the neutralization number of fatty acids by $4 \%$, yield - by $16.2 \%$.

The results of the study make it possible to produce fatty acids from soapstock by two-stage technology with high yield and neutralization number

Keywords: soapstock, fatty acids, saponification reaction, decomposition with sulfuric acid, neutralization number

\section{TECHNOLOGY DEVELOPMENT OF FATTY ACIDS OBTAINING FROM SOAPSTOK USING SAPONIFICATION}

Natalia Sytnik

Corresponding author $\mathrm{PhD}$

Department of Studies of Technology for Processing Oils and Fats Ukrainian Research Institute of Oils and Fats of National Academy of Agrarian Sciences of Ukraine Dziuby ave., 2a, Kharkiv, Ukraine, 61019 E-mail: ntlsytnik@gmail.com Ek a terina Kunitsia $\mathrm{PhD}$

Cycle Commission Hotel and Restaurant Business Separate Structural Subdivision «Housing and Municipal Professional College of O. M. Beketov National University of Urban Economy in Kharkiv» Shevchenka str., 233A, Kharkiv, Ukraine, 61033

Viktori a Kalyna

$\mathrm{PhD}$, Associate Professor Department of Technology of Storage and Processing of Agricultural Products Dnipro State Agrarian and Economic University Serhiya Yefremova str., 25, Dnipro, Ukraine, 49600

O I e a Petukhova $\mathrm{PhD}$, Associate Professor* Kostiantyn Ostapov $\mathrm{PhD*}$

Volodym y r I sh chuk Lecturer Department of Service and Training**

D m y tro Saveliev $\mathrm{PhD}$

Department of Engineering and Rescue Machinery**

Tetiana Kovalova $\mathrm{PhD}$, Associate Professor Department of Account and Taxation Kharkiv National Automobile and Highway University Yaroslava Mudroho str., 25, Kharkiv, Ukraine, 61002

O I e $\mathrm{g}$ ostyrkin

PhD, Associate Professor Department of Occupational Safety and Environmental Protection Ukrainian State University of Railway Transport Feierbakha sq., 7, Kharkiv, Ukrainian, 61050

O Ien a Petrova

$\mathrm{PhD}$, Associate Professor Department of Technology of Processing, Standardization and Certification of Livestock Products

Mykolayiv National Agrarian University Heorhiya Honhadze str., 9, Mykolayiv, Ukraine, 54020 *Department of Fire Prevention in Settlements** **National University of Civil Defence of Ukraine Chernyshevska str., 94, Kharkiv, Ukraine, 61023
Received date 05.09.2021 Accepted date 12.10.2021 Published date 29.10.2021
How to Cite: Sytnik, N., Kunitsia, E., Kalyna, V., Petukhova, O., Ostapov, K., Ishchuk, V., Saveliev, D., Kovalova, T., Kostyrkin, O., Petrova, O. (2021). Technology development of fatty acids obtaining from soapstok using saponification. Eastern-European Journal of Enterprise Technologies, 5 (6 (113)), 16-23. doi: https://doi.org/10.15587/1729-4061.2021.241942

\section{Introduction}

The main components of soapstock (waste of alkaline oil refining) are fats (up to $70 \%$ ), fatty acids (up to $30 \%$ ) and their sodium soaps, phospholipids, unsaponifiable and waxy substances, dyes. Depending on the fatty acid composition of the raw material and the concentration of the alkali solution used in the neutralization technology, the composition and 
properties of soapstock, its structure and viscosity change. Disposal of this waste without recycling leads to environmental pollution [1]. Fatty components of soapstock are capable of oxidation and pose a fire hazard [2]. The problem of fire danger and environmental pollution is important for industry and society as a whole. Special measures are being taken to prevent and reduce the effects of hazardous factors on humans and the environment. Reducing the fire hazard in the premises, the study of dangerous factors of fires and the development of advanced fire automation systems is an important area of modern research [3]. It is also important to develop new methods for the rapid detection of dangerous air pollution. Such methods allow to promptly detect overt and covert dangerous air pollution and increase the effectiveness and timeliness of measures to prevent air pollution in order to protect people and the environment [4]. The construction of industrial facilities requires strict compliance with regulatory requirements, the implementation of constructive calculations, taking into account the impact of possible hazards during the operation of an enterprise [5].

Important components of soapstock are fats and higher fatty acids. These components are used in the production of various industries, in particular, surfactants, higher fatty alcohols, hydrocarbons [6].

Topical issues are the creation of production schemes for low-waste technology and the development of new concepts for fatty waste processing [7]. Soapstock processing will allow obtaining marketable products for various purposes (fatty acids, detergents, etc.), among which the most valuable products are fatty acid esters, on the basis of which alternative biodiesel fuel is produced [8].

Therefore, research aimed at developing and improving technologies for oil processing waste from the oil and fat industry, in particular, soapstock, is extremely important. The key issue is to increase the efficiency of production and quality of fatty acids, the demand for which is consistently high.

\section{Literature review and problem statement}

Soapstock, which is formed during alkaline oil refining, is a valuable source of fatty acids, while creating the problem of processing, storage and disposal. Demand and cost of fatty acids are much higher than of soapstock. The cost of soapstock is $130 \$ / t$, the cost of fatty acids reaches $880 \$ / t$ [9].

According to [10], one of the most important uses of soapstock is the production of fatty acids for biodiesel fuel (fatty acid esters of low molecular weight monohydric alcohols - often methyl or ethyl). But in biodiesel production, the issue of raw materials remains open, because oils and fats are inexpedient raw materials due to their cost. The cost of sunflower oil reaches $700 \$ / \mathrm{t}$. The work [11] notes that the use of oil industry waste, in particular, soapstock, is promising. This approach solves a number of environmental problems and provides raw materials for biodiesel production.

The work [4] shows the problem of air pollution associated with the use of traditional fuel in diesel engines. The addition of biodiesel reduces the toxicity of engine exhaust. But the question of developing an effective technology for the production of alternative fuels based on industrial waste remains open.

According to [12], the most appropriate way to remove fatty acids from soapstock is treatment with sulfuric acid.
In [9], scientific results on the esterification of fatty acids derived from soapstock, in which the content of fatty acids was $65.5 \%$ and the content of sulfuric acid $10400 \mathrm{mg} / \mathrm{kg}$ are presented. In order to reduce the sulfuric acid content, soapstock was pre-washed with sodium hydroxide solution, which increased the yield and improved the quality of methyl esters. However, the influence of the conditions of soapstock treatment with an alkali solution on the quality and yield of fatty acids, as well as the performance of methyl esters is not shown.

The authors of [13] studied the soapstock obtained from palm oil refining as a raw material for ethyl esters production. First, the lipid portion of the soapstock was saponified with a $50 \%$ sodium hydroxide solution, after which the sodium salts were used in the production of esters. The disadvantage of the study is the lack of data on the effect of soapstock saponification on the efficiency of fatty acid production (yield and quality).

In [14], data on the production of methyl esters of fatty acids from soybean soapstock are presented. The most effective method involves complete saponification of soapstock followed by acid treatment. This makes it possible to obtain fatty acids with a concentration of about $90 \%$. However, there are no data on the effect of soapstock saponification conditions on the quality of fatty acids and information on sunflower soapstock.

The authors [15] investigated various methods of sunflower soapstock processing in order to obtain fatty acids for the production of butyl esters. The optimal ester yield is determined by the method of soapstock treatment, which includes saponification and decomposition with sulfuric acid (the ester yield is $89.0 \%$ ). The disadvantage of the study is the lack of data on the influence of soapstock processing parameters on the yield and physicochemical parameters of fatty acids.

In [16], rational conditions for fatty acids obtaining from soapstock by decomposition with sulfuric acid were determined: temperature $(90-95)^{\circ} \mathrm{C}$, duration $40 \mathrm{~min}$. Under these conditions, the yield of fatty acids was $79.0 \%$, the neutralization number $-180.0 \mathrm{mg} \mathrm{KOH} / \mathrm{g}$. But the paper considers only one way to obtain fatty acids, there is no data on ways to increase the yield of fatty acids.

Thus, the issue of soapstock processing to remove fatty acids is an important area of research. Of particular interest is the use of fatty acids to produce biodiesel. However, there are insufficient data on the effect of different methods of soapstock processing on the yield and composition of fatty acids, as well as the efficiency of their use in biodiesel production. Preliminary soapstock saponification in order to increase the efficiency of fatty acid extraction is promising. But there is no data on the rational conditions of this process, which will allow obtaining fatty acids with maximum yield and improved quality. Therefore, the unresolved issue is to determine rational conditions for two-stage soapstock processing using saponification, as well as the impact of soapstock pre-saponification on the quality and yield of fatty acids.

\section{The aim and objectives of the study}

The aim of the study was to develop the technology for fatty acids obtaining from soapstock using the saponification stage. This will make it possible to introduce a 
two-stage technology of soapstock processing (pre-saponification with sodium hydroxide solution and decomposition with sulfuric acid) with increased yield and neutralization number of fatty acids.

To achieve the aim, the following objectives were accomplished:

- to study the organoleptic and physicochemical indicators of the experimental sunflower soapstock;

- to determine the influence of soapstock pre-saponification conditions on the yield and neutralization number of fatty acids and to determine rational soapstock saponification conditions;

- to conduct a comparative analysis of organoleptic, physicochemical indicators and composition of fatty acids obtained by two-stage technology with prior saponification, and fatty acids obtained without prior soapstock saponification.

\section{Materials and methods to study rational conditions for soapstock saponification}

\footnotetext{
4. 1. Examined materials and equipment used in the experiment

The following reagents and materials were used in this study:

- ethyl rectified alcohol, according to DSTU 4221:2003 (CAS 64-17-5);

- potassium hydroxide, reagent grade, according to acting normative documentation;

- sodium hydroxide, reagent grade, according to acting normative documentation;

- phenolphthalein, according to acting normative documentation;

- methyl orange, according to acting normative documentation;

- sulfuric acid, reagent grade, according to GOST 4204 (CAS 7664-93-9);

- calcium chloride, extra-pure grade, according to GOST 450 (CAS 10043-52-4).
}

4. 2. Procedure for determining the organoleptic and physicochemical indicators of sunflower soapstock

Organoleptic characteristics of soapstock are determined by the standard method according to DSTU 5033:2008 (Method for determining color, consistency and odor). International methods for determining organoleptic parameters: color - ISO 15305, consistency - AOCS Method Cc 16-60, odor - AOCS Cg 2-83. The mass fraction of moisture is determined by the standard method according to DSTU 4603:2006 (ISO 662). The mass fraction of total fat, mass fraction of fatty acids are determined by standard methods according to DSTU 5033:2008 (ISO 17189, IDF 194).

\section{3. Procedure of preliminary soapstock saponification}

Preliminary soapstock saponification was performed with the aqueous solution of sodium hydroxide. For each experiment, the concentration of alkali solution was used according to the experimental design. In each experiment, a fixed amount of sodium hydroxide (as a solution of various concentrations) was added $-15 \%$ by the weight of soapstock. A portion of the soapstock was placed in a heat-re- sistant conical flask, and the required amount of sodium hydroxide solution was added. The flask was mounted on an electric stove, fixed on a tripod, and a reflux condenser was connected to the flask. The saponification process was carried out under boiling conditions for a specified time (according to the experimental plan). After completion of the process, the mass was cooled to $60{ }^{\circ} \mathrm{C}$ and subjected to further treatment with sulfuric acid solution.

4. 4. Procedure of soapstock treatment with sulfuric acid solution

Treatment of pre-saponified soapstock with sulfuric acid was performed as follows. A portion of the pre-saponified soapstock was placed in a heat-resistant conical flask, water with the temperature of $60{ }^{\circ} \mathrm{C}$ in the amount of $50 \%$ by weight of the soapstock was added. The flask was mounted on an electric stove, a stirrer was placed in the flask. While stirring, sulfuric acid solution with a concentration of $40 \%$ was added to the flask. The amount of sulfuric acid was adjusted so that excess sulfuric acid was maintained throughout the treatment process. Excess acid was monitored by a methyl orange indicator. After adding the sulfuric acid solution, the mass was stirred at a given temperature for a given time. The resulting mass was settled for $4-5$ hours. The obtained upper layer of fatty acids was washed with hot water until the complete removal of sulfuric acid, which was controlled by methyl orange. The absence of sulfate ions was checked using the calcium chloride solution with a concentration of $10 \%$.

4. 5. Procedure for determining the organoleptic, physicochemical indicators and composition of fatty acids

The neutralization number of fatty acids is determined as follows. A portion of fatty acids about $2.0 \mathrm{~g}$ is dissolved in $(40-60) \mathrm{cm}^{3}$ of ethyl alcohol. Then $0.5 \mathrm{~cm}^{3}$ of phenolphthalein solution is added and titrated with $0.5 \mathrm{~N}$ aqueous or alcoholic solution of potassium hydroxide to a pink color that does not disappear within 30 seconds. The neutralization number $(N N)$ is calculated by the formula:

$$
N N=\frac{V \cdot 28.05 \cdot K}{P},
$$

where $V$ - the amount of $0.5 \mathrm{~N}$ potassium hydroxide solution, which went to titration, $\mathrm{cm}^{3} ; 28.05$ - titer of exactly $0.5 \mathrm{~N} \mathrm{KOH}$ solution multiplied by $1000 ; K$ - correction to a titer of $0.5 \mathrm{~N}$ potassium hydroxide solution; $P$ - portion of fatty acids, g. The organoleptic parameters, mass fraction of total fat, cleavage depth, presence of mineral acids in fatty acids are determined by the standard method according to DSTU 4860:2007, mass fraction of moisture according to DSTU 4603:2006. The composition of fatty acids is determined by the standard method according to DSTU ISO 5508-2001 and DSTU ISO 5509-2002.

\section{6. Planning of experimental research and process- ing the results}

A full factorial experiment was used for research planning and mathematical data processing. Processing of scientific results, construction of graphical dependences are performed in the Stat Soft Statistica v6.0 software package (USA). Two experiments were performed for each experiment. 
5. Results of studying the influence of soapstock saponification conditions on the yield and neutralization number of fatty acids

5. 1. Determination of organoleptic and physicochemical indicators of experimental sunflower soapstock

Experimentally determined organoleptic and physicochemical indicators of soapstock are given in Table 1.

Table 1

Organoleptic and physicochemical indicators of soapstock

\begin{tabular}{|c|c|}
\hline Indicator & Characteristics \\
\hline \multicolumn{2}{|c|}{ Organoleptic indicators } \\
\hline Color & Light brown \\
\hline Consistency at $20{ }^{\circ} \mathrm{C}$ & Oily \\
\hline Odor & $\begin{array}{c}\text { Characteristic of sunflower oil } \\
\text { soapstock }\end{array}$ \\
\hline \multicolumn{2}{|c|}{ Physicochemical indicators } \\
\hline $\begin{array}{c}\text { Mass fraction of moisture and } \\
\text { volatile substances, } \%\end{array}$ & 16.2 \\
\hline Mass fraction of total fat, \% & 68.5 \\
\hline Mass fraction of fatty acids, $\%$ & 62.6 \\
\hline Mass fraction of neutral fat, \% & 5.9 \\
\hline
\end{tabular}

Therefore, the experimental sample of sunflower soapstock complies in organoleptic and physicochemical indicators with DSTU 5033 (CAS 68952-95-4).

5. 2. Determining the influence of soapstock pre-saponification conditions on the yield and neutralization number of fatty acids

The method of fatty acids obtaining from soapstock was investigated, which includes two stages: preliminary soapstock saponification with sodium hydroxide solution; treatment of saponified soapstock with sulfuric acid solution. Treatment of saponified soapstock with sulfuric acid solution was performed under rational conditions, previously determined in [16]: temperature $(90-95){ }^{\circ} \mathrm{C}$, duration $40 \mathrm{~min}$. The influence of soapstock pre-saponification conditions on the yield and neutralization number of fatty acids: duration of saponification and concentration of sodium hydroxide solution was determined. The full factorial experiment was used: number of factors -2 , number of levels of factor variation -5 , number of experiments -25 .

Factors and intervals of variation: $x_{1}$ - duration of preliminary soapstock saponification: from 30 to $90 \mathrm{~min}$. (30, $45,60,75,90 \mathrm{~min}$.); $x_{2}$ - concentration of aqueous solution of sodium hydroxide: from 30 to $50 \%(30,35,40,45,50 \%)$. The response functions were the yield ( $\%$ of available fatty acid content in soapstock) and the neutralization number of fatty acids obtained by two-stage technology. Table 2 shows the matrix of experiment planning and experimental values of response functions.

The obtained experimental data show the nonlinearity of the dependence of the response functions on the variation factors and the presence of extremums.

As a result of processing experimental data in the Stat Soft Statistica v6.0 package environment (USA), mathematical models (second-order regression equations) are obtained, which are the dependences of the response functions on the soapstock pre-saponification conditions. Response functions are marked as follows: $y_{1}-$ yield of fatty acids, $\% ; y_{2}-$ neutralization number of fatty acids, mg $\mathrm{KOH} / \mathrm{g}$.
Table 2

Matrix of experiment planning and values of response functions

\begin{tabular}{|c|c|c|c|c|}
\hline $\begin{array}{c}\text { Exper- } \\
\text { iment } \\
\text { number }\end{array}$ & \begin{tabular}{c|} 
Duration of \\
soapstock \\
saponifica- \\
tion, min \\
\end{tabular} & $\begin{array}{c}\text { Concentra- } \\
\text { tion of sodium } \\
\text { hydroxide } \\
\text { solution, } \% \\
\end{array}$ & $\begin{array}{c}\text { Fatty } \\
\text { acid } \\
\text { yield, \% }\end{array}$ & $\begin{array}{c}\text { Neutralization } \\
\text { number of } \\
\text { fatty acids, mg } \\
\mathrm{KOH} / \mathrm{g}\end{array}$ \\
\hline 1 & 30 & 30 & 53.6 & 97.3 \\
\hline 2 & 30 & 35 & 54.5 & 112.1 \\
\hline 3 & 30 & 40 & 60.8 & 126.7 \\
\hline 4 & 30 & 45 & 74.1 & 127.7 \\
\hline 5 & 30 & 50 & 89 & 129.1 \\
\hline 6 & 45 & 30 & 55.1 & 99.8 \\
\hline 7 & 45 & 35 & 56.1 & 115.7 \\
\hline 8 & 45 & 40 & 63.2 & 129.5 \\
\hline 9 & 45 & 45 & 76.8 & 130.7 \\
\hline 10 & 45 & 50 & $\begin{array}{l}90.9 \\
\end{array}$ & 134.7 \\
\hline 11 & 60 & 30 & 68 & 129.9 \\
\hline 12 & 60 & 35 & 68.3 & 139.8 \\
\hline 13 & 60 & 40 & 69.7 & 148 \\
\hline 14 & 60 & 45 & 75.4 & 159.9 \\
\hline 15 & 60 & 50 & 81.9 & 170.1 \\
\hline 16 & 75 & 30 & 70.1 & 133.1 \\
\hline 17 & 75 & 35 & 71 & 142.5 \\
\hline 18 & 75 & 40 & 73.2 & 152.1 \\
\hline 19 & 75 & 45 & 77.8 & $\begin{array}{l}163.8 \\
\end{array}$ \\
\hline 20 & 75 & 50 & 83.4 & 175.7 \\
\hline 21 & 90 & 30 & 83.2 & 179.5 \\
\hline 22 & 90 & 35 & 85.1 & 183.5 \\
\hline 23 & 90 & 40 & 89.5 & 186.2 \\
\hline 24 & 90 & 45 & 92.4 & 187.5 \\
\hline 25 & 90 & 50 & 95.4 & 188.1 \\
\hline
\end{tabular}

The regression dependence of the fatty acid yield on the soapstock pre-saponification conditions in real variables is:

$$
\begin{aligned}
& y_{1}=59.87+0.44 \cdot x_{1}-1.89 \cdot x_{2}+ \\
& +0.01 \cdot x_{1}^{2}-0.02 \cdot x_{1} \cdot x_{2}+0.05 \cdot x_{2}^{2}
\end{aligned}
$$

The regression dependence of the neutralization number of fatty acids on the soapstock pre-saponification conditions in real variables is:

$$
\begin{aligned}
& y_{1}=-45.56+0.36 \cdot x_{1}+5.69 \cdot x_{2}+ \\
& +0.01 \cdot x_{1}^{2}-0.01 \cdot x_{1} \cdot x_{2}-0.04 \cdot x_{2}^{2} .
\end{aligned}
$$

The adequacy of the mathematical models was checked by the level of significance of the coefficients of equations $(p>0.05)$ and the values of the determination coefficients ( 0.926690 and 0.950084 , respectively). Table 3 shows the estimated values of the response functions - yield and neutralization number of fatty acids, calculated by dependences (2) and (3), respectively (experimental numbers correspond to Table 2).

Graphic images of the response surfaces are constructed, which represent the dependence of the yield (Fig. 1) and neutralization number (Fig. 2) of fatty acids on the duration of soapstock saponification and concentration of aqueous sodium hydroxide solution. 
Table 3 Neutralization number,

Estimated values of response functions

\begin{tabular}{|c|c|c|}
\hline $\begin{array}{c}\text { Experiment } \\
\text { number }\end{array}$ & $\begin{array}{c}\text { Fatty acid } \\
\text { yield, } \%\end{array}$ & $\begin{array}{c}\text { Neutralization number of fatty } \\
\text { acids, } \mathrm{mg} \text { KOH }\end{array}$ \\
\hline 1 & 58.55 & 97.21 \\
\hline 2 & 60.05 & 105.05 \\
\hline 3 & 64.32 & 112.90 \\
\hline 4 & 71.36 & 120.74 \\
\hline 5 & 81.16 & 128.58 \\
\hline 6 & 59.00 & 113.62 \\
\hline 7 & 60.50 & 121.46 \\
\hline 8 & 64.77 & 129.31 \\
\hline 9 & 71.81 & 137.15 \\
\hline 10 & 81.62 & 145.00 \\
\hline 11 & 62.63 & 130.03 \\
\hline 12 & 64.13 & 137.88 \\
\hline 13 & 68.40 & 145.72 \\
\hline 14 & 75.44 & 153.56 \\
\hline 15 & 85.25 & 161.41 \\
\hline 16 & 69.43 & 146.44 \\
\hline 17 & 70.93 & 154.29 \\
\hline 18 & 75.20 & 162.13 \\
\hline 19 & 82.24 & 169.98 \\
\hline 20 & 92.04 & 177.82 \\
\hline 21 & 79.40 & 162.86 \\
\hline 22 & 80.90 & 170.70 \\
\hline 23 & 85.17 & 178.54 \\
\hline 24 & 92.21 & 186.39 \\
\hline 25 & 102.01 & 194.23 \\
\hline & & \\
\hline
\end{tabular}

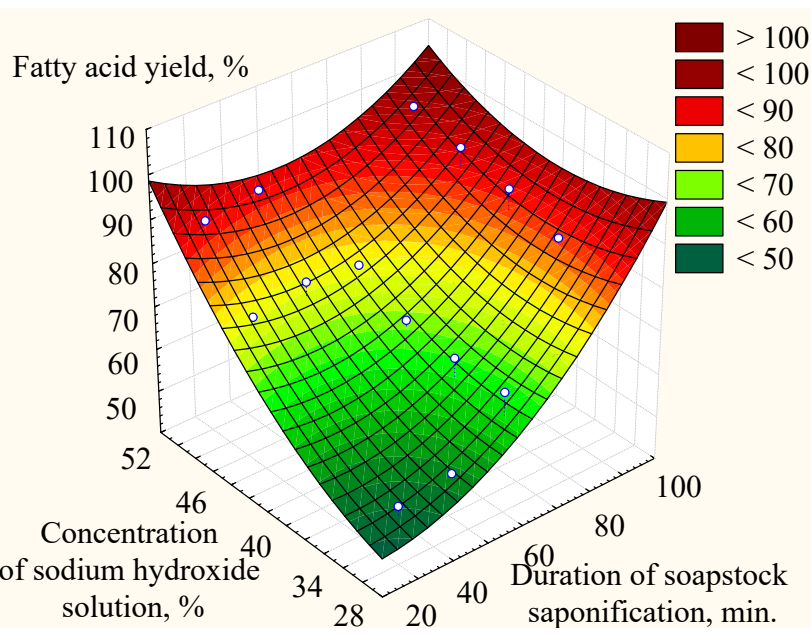

Fig. 1. Dependence of fatty acid yield on the duration of soapstock saponification and concentration of sodium hydroxide solution

By equation (2) and Fig. 1, it was found that saponification duration has a greater effect on the acid yield than the concentration of sodium hydroxide solution. Starting with the duration of $85 \mathrm{~min}$., the highest yield values are observed. The maximum yield values correspond to the concentration of the alkali solution starting from $45 \%$. Subsequent increases in these parameters do not lead to a significant increase in the response function. Therefore, the following conditions are rational: duration $85 \mathrm{~min}$., concentration of alkali solution $45 \%$. In this case, the yield is $91.8 \%$.

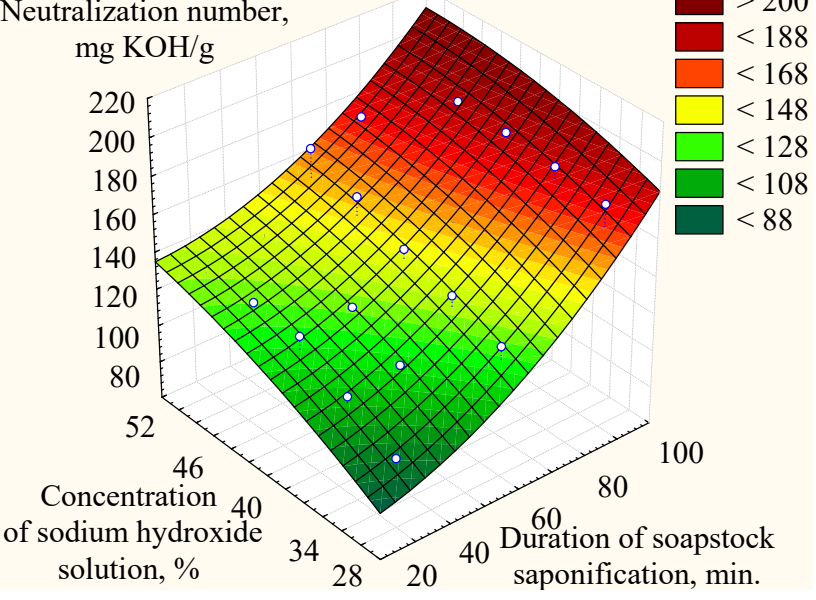

Fig. 2. Dependence of neutralization number of fatty acids on the duration of soapstock saponification and concentration of sodium hydroxide solution

By equation (3) and Fig. 2, it was found that saponification duration also significantly affects the neutralization number of fatty acids. The highest values (with a gradual decrease in increasing) of the neutralization number are observed, ranging from the alkali concentration (45-50) \% and duration (85$90)^{\circ} \mathrm{C}$. Consequently, the following conditions are rational: duration 85 min., concentration of alkaline solution $45 \%$. In this case, the neutralization number is $187.1 \mathrm{mg} \mathrm{KOH} / \mathrm{g}$.

5. 3. Comparative analysis of qualitative indicators of fatty acids obtained with soapstock saponification and without saponification

In comparison with the data [16], the use of two-stage soapstock processing technology using saponification led to the increase in the neutralization number of acids by $4 \%$, yield - by $16.2 \%$ under rational conditions. Table 4 presents the quality indicators of fatty acids obtained without saponification [16] and by two-stage technology with saponification (under rational conditions).

Table 4

Quality indicators of fatty acids obtained under rational conditions

\begin{tabular}{|c|c|c|}
\hline \multirow{2}{*}{ Indicator } & \multicolumn{2}{|c|}{ Characteristics } \\
\cline { 2 - 3 } & $\begin{array}{c}\text { Fatty acids } \\
\text { obtained with } \\
\text { saponification }\end{array}$ & $\begin{array}{c}\text { Fatty acids ob- } \\
\text { tained without } \\
\text { saponification }\end{array}$ \\
\hline Color at $20^{\circ} \mathrm{C}$ & \multicolumn{2}{|c|}{ Brown } \\
\hline Odor & \multicolumn{2}{|c|}{ Specific to fatty acids } \\
\hline $\begin{array}{c}\text { Mass fraction of moisture } \\
\text { and volatile substances, } \%\end{array}$ & 1.5 & 1.8 \\
\hline Mass fraction of total fat, $\%$ & 98.0 & 97.0 \\
\hline $\begin{array}{c}\text { Cleavage depth, } \% \\
\text { oleic acid }\end{array}$ & 69.2 & 64.5 \\
\hline Presence of mineral acids & \multicolumn{2}{|c|}{ Absent } \\
\hline
\end{tabular}

According to Table 4, it was found that the fatty acids obtained with soapstock saponification are of high quality. The indicators correspond to the characteristics of fatty acids of light oils and modified fats, obtained without saponification, of the first grade according to DSTU 4860 (CAS 61788-66-7). 
In this case, these fatty acids have better indicators than acids obtained without saponification (higher mass fraction of total fat and cleavage depth).

A comparative analysis of the composition of fatty acids obtained with saponification, without soapstock saponification and fatty acid composition of sunflower oil was performed (Table 5). The composition of fatty acids obtained without saponification and sunflower oil is presented according to [16].

Table 5

Composition of the obtained fatty acids and the fatty acid composition of sunflower oil

\begin{tabular}{|c|c|c|c|c|}
\hline \multirow[b]{2}{*}{ No. } & \multirow[b]{2}{*}{ Fatty acid } & \multicolumn{3}{|c|}{ Mass fraction of fatty acids, $\%$} \\
\hline & & $\begin{array}{c}\text { Fatty acids } \\
\text { obtained with } \\
\text { saponification }\end{array}$ & $\begin{array}{l}\text { Fatty acids ob- } \\
\text { tained without } \\
\text { saponification }\end{array}$ & $\begin{array}{l}\text { Sun- } \\
\text { flower } \\
\text { oil }\end{array}$ \\
\hline 1 & Palmitic $\mathrm{C}_{16: 0}$ & 1.0 & 0 & 1.7 \\
\hline 2 & Palmitoleic $\mathrm{C}_{16: 1}$ & 0.4 & 0.7 & 0.2 \\
\hline 3 & Stearic $\mathrm{C}_{18: 0}$ & 6.0 & 6.9 & 3.6 \\
\hline 4 & Oleic $\mathrm{C}_{18: 1}$ & 35.4 & 37.4 & 30.9 \\
\hline 5 & Linoleic $\mathrm{C}_{18: 2}$ & 54.8 & 51.2 & 62.3 \\
\hline 6 & Linolenic $\mathrm{C}_{18: 3}$ & 0 & 0 & 0.1 \\
\hline 7 & Arachinic $\mathrm{C}_{20: 0}$ & 0.4 & 0.4 & 0.2 \\
\hline 8 & Gadoleic $\mathrm{C}_{20: 1}$ & 0.3 & 0.8 & 0.1 \\
\hline 9 & Behenic $\mathrm{C}_{22: 0}$ & 0.9 & 1.2 & 0.7 \\
\hline 10 & Lignoceric $\mathrm{C}_{24: 0}$ & 0.3 & 0.4 & 0.2 \\
\hline 11 & Myristic $\mathrm{C}_{14: 0}$ & 0.5 & 1.0 & 0 \\
\hline & Total & 100.0 & 100.0 & 100.0 \\
\hline
\end{tabular}

Therefore, the composition of fatty acids obtained with saponification is closer to the fatty acid composition of sunflower oil than the composition of fatty acids obtained without soapstock saponification.

\section{Discussion of the results of studying the dependence of soapstock saponification conditions on the influence on the indicators of fatty acid obtaining}

The two-stage technology of soapstock processing for the purpose of fatty acid extraction, which consists of preliminary saponification and decomposition with sulfuric acid, is investigated. The decomposition stage with sulfuric acid was performed under the rational conditions determined in [16]: temperature $(90-95)^{\circ} \mathrm{C}$, duration $40 \mathrm{~min}$. The influence of soapstock saponification conditions on the yield and neutralization number, which characterize the efficiency of the fatty acid production process, has been determined. Rational saponification conditions: duration $85 \mathrm{~min}$., concentration of sodium hydroxide solution $45 \%$. Under these conditions, the yield of fatty acids was $91.8 \%$, the neutralization number - $187.1 \mathrm{mg} \mathrm{KOH} / \mathrm{g}$.

The work is a continuation of the research presented in [16], which considered the extraction of fatty acids in one stage (decomposition with sulfuric acid). Under rational conditions, the yield of fatty acids was $79.0 \%$, the neutralization number $-180.0 \mathrm{mg} \mathrm{KOH} / \mathrm{g}$. Thus, the use of two-stage soapstock processing technology can increase the efficiency of fatty acid extraction: increase the yield of fatty acids by $16.2 \%$, the neutralization number - by $4 \%$.
Comparative analysis of the quality of fatty acids obtained with saponification and without saponification shows an improvement in the quality of acids obtained in two stages. Thus, acids obtained with saponification have higher indicators of mass fraction of total fat $(98.0 \%)$ and cleavage depth $(69.2 \%)$ than the corresponding indicators for acids obtained without saponification (97.0 and $64.5 \%$ ). In both cases, the indicators of the obtained fatty acids meet the requirements of DSTU 4860 (CAS 61788-66-7). According to Table 5, it was found that the composition of fatty acids obtained by the two-stage method is closer to the fatty acid composition of sunflower oil.

The work differs from the existing [11, 16-18] scientific developments in the extraction of fatty acids from soapstocks by studying the conditions of the two-stage technology of soapstock processing. This technology makes it possible to obtain fatty acids with improved quality and yield.

Increasing the concentration of sodium hydroxide leads to the increase in the yield and neutralization number of acids by increasing the intensity of mass transfer and more complete conversion of the soapstock lipid part into soap at the stage of saponification. As a result, more fatty acids in the form of soaps enter the stage of acid decomposition, which leads to increased yield. So, for the process duration of $30 \mathrm{~min}$. with increasing the concentration of alkali solution from 30 to $50 \%$, the yield increases 1.7 times, the neutralization number - 1.3 times (Table 2, Fig. 1, 2). Increasing the saponification duration also increases the value of the response functions. Under conditions of alkali concentration of $30 \%$ as a result of increasing the duration from 30 to $90 \mathrm{~min}$., the acid yield increases 1.6 times, the neutralization number - 1.8 times (Table 1, Fig. 1, 2). That is, saponification duration has a more significant effect on the neutralization number than the alkali concentration. The yield of fatty acids is significantly influenced by both factors of variation.

According to Fig. 1, 2, it was found that the maximum values of yield and neutralization number of acids are observed under conditions of concentration of sodium hydroxide solution from $45 \%$ and process duration from $85 \mathrm{~min}$. Reducing the saponification duration requires increasing the concentration of sodium hydroxide solution. However, as saponification duration significantly affects the neutralization number, it is impractical to reduce this parameter. Thus, the rational concentration of sodium hydroxide is $45 \%$, saponification duration is $85 \mathrm{~min}$.

The implementation of the obtained scientific results requires compliance with rational conditions and high-quality reagents in the processes of saponification and treatment with sulfuric acid. When using sodium hydroxide, it is necessary to determine and take into account the actual concentration of the basic substance in the dry product. This substance is hygroscopic and during storage absorbs moisture, carbon dioxide from the air, which leads to the formation of sodium carbonate, increases the moisture content and reduces the concentration of basic alkali.

When using the results of the study, it is necessary to adhere to the rational duration of soapstock pre-saponification (85 min.), as this parameter most significantly affects the yield and neutralization number of fatty acids. Reducing the duration can lead to lower-quality fatty acids. The developed mathematical models can be used within 
the experimental limits of the values of factors: duration of preliminary soapstock saponification: from 30 to $90 \mathrm{~min}$.; concentration of aqueous sodium hydroxide solution: from 30 to $50 \%$. In the case of values of factors that go beyond the study, additional experiments are needed to predict the yield and neutralization number of fatty acids.

The disadvantage of the study is the use of dangerous sulfuric acid. It is advisable to conduct a number of studies to neutralize and reduce the negative environmental impact of wash water after purification of the final fatty acids from sulfuric acid. But the use of sulfuric acid is an effective way to process soapstocks in order to obtain a valuable target product - fatty acids.

Promising areas of research are to determine the impact of soapstock processing conditions directly on the production process and quality indicators of biodiesel. This is important because soapstock is primarily seen as an available raw material for the production of alternative fuels.

\section{Conclusions}

1. Organoleptic and physicochemical indicators of the experimental sample of soapstock were studied. Soapstock has the following characteristics: mass fraction of mois- ture $-15.4 \%$, total fat $-68.5 \%$, fatty acids $-62.6 \%$, neutral fat $-5.9 \%$. The experimental sample of soapstock complies with DSTU 5033 (CAS 68952-95-4).

2. The influence of the conditions of preliminary soapstock saponification on the yield and neutralization number of fatty acids was determined. The corresponding dependences are obtained in mathematical and graphical form. Rational conditions of soapstock saponification were determined: duration (85 min.) and concentration of sodium hydroxide solution ( $45 \%$ ). Under these conditions, the yield of fatty acids was $91.8 \%$, the neutralization number was $187.1 \mathrm{mg} \mathrm{KOH} / \mathrm{g}$.

3. A comparative analysis of the quality indicators and composition of fatty acids obtained by two-stage technology with pre-saponification and fatty acids obtained without soapstock saponification was performed. The introduction of two-stage technology of soapstock processing with saponification allows increasing the neutralization number of fatty acids by $4 \%$, yield - by $16.2 \%$ under rational conditions. Fatty acids obtained with soapstock saponification have a higher mass fraction of total fat $(98.0 \%)$ and cleavage depth $(69.2 \%)$ than acids obtained without saponification (97.0 and $64.54 \%$, respectively). The composition of fatty acids obtained with saponification is closer to the fatty acid composition of sunflower oil.

\section{References}

1. Barbusiński, K., Fajkis, S., Szeląg, B. (2021). Optimization of soapstock splitting process to reduce the concentration of impurities in wastewater. Journal of Cleaner Production, 280,124459. doi: https://doi.org/10.1016/j.jclepro.2020.124459

2. Sytnik, N., Kunitsia, E., Mazaeva, V., Chernukha, A., Kovalov, P., Grigorenko, N. et. al. (2020). Rational parameters of waxes obtaining from oil winterization waste. Eastern-European Journal of Enterprise Technologies, 6 (10 (108)), 29-35. doi: https:// doi.org/10.15587/1729-4061.2020.219602

3. Pospelov, B., Rybka, E., Meleshchenko, R., Gornostal, S., Shcherbak, S. (2017). Results of experimental research into correlations between hazardous factors of ignition of materials in premises. Eastern-European Journal of Enterprise Technologies, 6 (10 (90)), 50-56. doi: https://doi.org/10.15587/1729-4061.2017.117789

4. Pospelov, B., Rybka, E., Meleshchenko, R., Borodych, P., Gornostal, S. (2019). Development of the method for rapid detection of hazardous atmospheric pollution of cities with the help of recurrence measures. Eastern-European Journal of Enterprise Technologies, 1 (10 (97)), 29-35. doi: https://doi.org/10.15587/1729-4061.2019.155027

5. Otrosh, Y., Semkiv, O., Rybka, E., Kovalov, A. (2019). About need of calculations for the steel framework building in temperature influences conditions. IOP Conference Series: Materials Science and Engineering, 708, 012065. doi: https://doi.org/10.1088/ $1757-899 x / 708 / 1 / 012065$

6. Malins, K. (2021). Production of renewable hydrocarbons from vegetable oil refining by-product/waste soapstock over selective sulfur-free high metal loading $\mathrm{SiO}_{2}-\mathrm{Al}_{2} \mathrm{O}_{3}$ supported Ni catalyst via hydrotreatment. Journal of Cleaner Production, 283, 125306. doi: https://doi.org/10.1016/j.jclepro.2020.125306

7. Vambol, S., Vambol, V., Kondratenko, O., Koloskov, V., Suchikova, Y. (2018). Substantiation of expedience of application of hightemperature utilization of used tires for liquefied methane production. Journal of Achievements in Materials and Manufacturing Engineering, 2 (87), 77-84. doi: https://doi.org/10.5604/01.3001.0012.2830

8. Cruz, M., Pinho, S. C., Mota, R., Almeida, M. F., Dias, J. M. (2018). Enzymatic esterification of acid oil from soapstocks obtained in vegetable oil refining: Effect of enzyme concentration. Renewable Energy, 124, 165-171. doi: https://doi.org/10.1016/ j.renene.2017.06.053

9. Mashhadi, F., Habibi, A., Varmira, K. (2018). Enzymatic production of green epoxides from fatty acids present in soapstock in a microchannel bioreactor. Industrial Crops and Products, 113, 324-334. doi: https://doi.org/10.1016/j.indcrop.2018.01.052

10. Kondratenko, O. M., Vambol, S. O., Strokov, O. P., Avramenko, A. M. (2015). Mathematical model of the efficiency of diesel particulate matter filter. Naukovyi visnyk Natsionalnoho hirnychoho universytetu, 6, 55-61. Available at: http://www.nvngu.in.ua/ index.php/en/component/jdownloads/finish/57-06/8434-2015-06-kondratenko/0 
11. Pantoja, S., Mescouto, V., Costa, C., Zamian, J., Rocha Filho, G., Nascimento, L. (2018). High-Quality Biodiesel Production from Buriti (Mauritia flexuosa) Oil Soapstock. Molecules, 24 (1), 94. doi: https://doi.org/10.3390/molecules24010094

12. Dunn, R. O. (2021). Correlating the cloud point of biodiesel with its fatty acid methyl ester composition: Multiple regression analyses and the weighted saturation factor (wSF). Fuel, 300, 120820. doi: https://doi.org/10.1016/j.fuel.2021.120820

13. Ferrero, G. O., Faba, E. M. S., Eimer, G. A. (2021). Biodiesel production from alternative raw materials using a heterogeneous low ordered biosilicified enzyme as biocatalyst. Biotechnology for Biofuels, 14 (1). doi: https://doi.org/10.1186/s13068-021-01917-x

14. Alishahi, A., Golmakani, M., Niakousari, M. (2021). Feasibility Study of Microwave Assisted Biodiesel Production from Vegetable Oil Refinery Waste. European Journal of Lipid Science and Technology, 123 (9), 2000377. doi: https://doi.org/10.1002/ejlt.202000377

15. Demidov, I., Sytnik, N., Mazaeva, V. (2014). Sunflower and problem alternative fuel in Ukraine. Naukovo-tekhnichnyi biuleten Instytutu oliynykh kultur NAAN, 21, 137-146. Available at: http://nbuv.gov.ua/UJRN/znpiok_2014_21_22

16. Sytnik, N., Kunitsia, E., Mazaeva, V., Kalyna, V., Chernukha, A., Vazhynskyi, S. et. al. (2021). Rational conditions of fatty acids obtaining by soapstock treatment with sulfuric acid. Eastern-European Journal of Enterprise Technologies, 4 (6 (112)), 6-13. doi: https://doi.org/10.15587/1729-4061.2021.236984 